\title{
Mobile Phone and Pakistani Youth: A Gender Perspective
}

\author{
Zarqa S. Ali \\ Department of Film, Television and Media Studies \\ University of Auckland, New Zealand \\ Level 4, Arts 2, 18 Symonds Street, Auckland, New Zealand \\ email: zsha016@aucklanduni.ac.nz
}

\begin{abstract}
This research was designed to open a window on youngsters' use of mobile phone. The present study examined the purposes and patterns of usage of mobile phone use- in both male and female students of undergraduate and graduate level at seven public sector universities of the Province of Punjab (Pakistan). The study examined and reviewed the literature to understand the patterns and purposes of mobile phone use from a global perspective in both developed and developing societies. This provided in a context for the study of mobile phone use in the local Pakistani situation. The findings of the study conclude that gender differences exist in purposes and patterns of usage of mobile phone use, though they are not very significant. There is a change in the trend among females as the usage of the mobile phone is increasing. Contrary to the general perception about gender conscious Pakistani society, females are almost on par with males in using mobile phone. However, existing gender stereotypes maintain the status quo in terms of purposes of using mobile phone.
\end{abstract}

Keywords: Gender, Mobile Phone, University students, Pakistan

\section{Introduction}

Mobile phone has made it possible to access required information almost instantaneously. The virtually immediate delivery and receipt of information through mobile phone has the power to save a person from many difficulties or crises, even, in many cases, saving life itself, and it has produced a new wave of empowerment in both male and female members of society. Though mobile phone has become equally diffused throughout all social strata, youngsters are heavy users of mobile phone all over the world [1]. In general, mobile phone has become an indispensable part of the lives of the young and is considered more than a gadget of communication. The pace of adoption of mobile phones is far ahead of computers, the Internet and email. The results of demographic longitudinal study of mobile phones in London, Paris and Madrid reveal a fast pace of changes paralleling spreading mobile usage, across different age groups, places, times and situations. The number of mobile phones and mobile phone users are growing fast in these countries and Pakistan is not exception of this mushroom growth of mobile phone users [2]. Mobile phone is very popular means of communication, which is used both for sending and receiving text messages. Short Messaging Service (SMS) is a text messaging service through mobile phone that has been a hit with teenagers and business people in various continents of the world like the United States and Europe and penetrating into Asia [3, 4]. It is now in Pakistan as well.

Mobile phone has become a status symbol and a day to day life organizer gadget. It has been observed that not-having a cell-phone or the loss of a mobile phone is giving people a sense of exclusion. Convergence of many technologies in mobile phones for various and numerous functions has extremely attached the youth with mobile phone. It has replaced some conventional devices like cameras and diaries. Earlier, phones were mostly used for calls, but now they are being used as multipurpose appliances with convergent technologies and are being used for multimedia messaging services, web-browsing, recording music and videos, radio, downloading polyphonic ring tones, taking photographs and even as private secretaries as they can wake one up at a given time, remind one of important events, meetings and other tasks and can be used to keep a diary of events. The compulsive checking and inappropriate use of mobile phones are symptoms of addiction. Youth' social withdrawal even being in public 
but fully composed and lost in cell-phone-world with the facilitation of their mobile phones has been observed.

Mobile communication technologies are being used everywhere, in private and public. When mobile phone use occurs in public places, it becomes pertinent to follow some etiquette, because others are affected. Sometimes behavior of mobile phone users in public considered inappropriate when they do not follow the generally approved etiquettes $[5,6]$. People think it is inappropriate to use mobile phones during worship, class, in a library or movie, and it is contrarily considered appropriate to use cell phones on public transport, in a supermarket, restaurants, and washrooms and through a hand free set while driving. Females are less likely to approve of the use of cell phones during driving and worship but otherwise have the same opinion as male counter-parts about generally approved etiquettes [7-9]. However, male are more involved in violation of mobile phone rule than females [10]. The feelings and emotions of users and non-users of mobile phones in public places are controlled by three factors: views about the application of public restrictions; desire to be personally contactable; and anxiety regarding annoyance regarding cell phone use in public [11]. However, social context has a significant impact on the use and perception of use of cell phones in public.

Mobile phone has become very important in developing and maintaining relationships. Mobile phones are affecting sociability and causing social change especially in urban areas and more particularly mobile phones are contributing to the moods or atmosphere of places with the changing moods of the users. Mobile phones are changing the users' subjectivities through their role attributing emotions, intimate relationships, and social obligations. Ling (2006) explores in his study that the use of mobile phones facilitates communication, development of relationships, understanding and romantic elements along with safety, unity and responsibility when he points out various uses of mobile phone in youth culture fulfilling their adolescent needs for example availability, emancipation, safety, micro-coordination and accessibility to others [12]. Mobile phone plays a major role in students' motivation, pressure, and performance in education. A survey of 120 female students of Madinah University, Saudi Arabia revealed that the main effects of smart phone use were reported to be on memory, sleep and concentration, which might impact on academic performance [13].

The traditional calling and use of text messaging are the most heavily used features and are used on daily basis [14]. However, text messaging through mobile phone is gaining popularity among users due to factors like cost, privacy, autonomy and reserved response facility. Text messaging has developed into a medium through which dialectical tensions are eased out; people say they use text messaging more than voice interaction for autonomy, privacy and continuity as well as interpersonal connectedness for communication with relational partners. Romantic pairs and non-romantic dyads consider the use of text messaging differently. Romantic pairs use text messaging for sharing romantic and sentimental feelings and emotions while non-romantic dyads use it for sharing social experiences and transferring information [15].

It has become imperative for every business setup to have specific mobile numbers for their employees. The use of mobile phone has become imperative in conducting the day to day affairs of business. Recently, the use of text messages as advertisement has also been noted. Mobile phone has played a pivotal role during the recent elections in Pakistan. On the one hand, it helped voters refine their decisions by sharing information about the candidates with their friends and family members, while on the other, the candidates used it to reach, influence and motivate the voters. Short messaging service (SMS) was used as a propaganda tool during the election campaigns.

\section{Research Method:}

The survey method was employed in the study to collect data from the participants to answer the research questions mentioned below as it was found to be the most cost effective way to reach the entire target population. The self-structured questionnaire was developed, taking into account the types of questions that were used in previous studies and items necessary to describe and reflect the usage of mobile phone in the universities of a developing country like Pakistan.

JTI Vol. 1, No. 2, July 2013: $59-68$ 


\subsection{Sampling Procedure}

The multistage sampling procedure was employed to select the sample of the study. In the first stage, seven public sector general education universities were selected keeping in view their geographical location for the maximum representation of the population of the province of Punjab. Hence, the sample of the study includes the following public sector universities:

1) Bahauddin Zakariya University, Multan;

2) University of Sargodha, Sargodha;

3) Government College University, Faisalabad;

4) Islamia University, Bahawalpur;

5) University of the Punjab, Lahore;

6) Fatima Jinnah Women University, Rawalpindi; and

7) University of Gujrat, Gujrat.

The researcher fixed these seven public sector universities of the province of Punjab, spreading from extreme south to north of the province, as Punjab is one of the largest provinces of Pakistan covering an area of 205344 Square Kms. All the students of these seven universities were the universe of the present study.

The total number of the sample of the study was $\mathrm{N}=858$ with the mean age 21.5 years. As the present study focused on gender difference regarding the use of ICTs, a sample was obtained of male respondents constituting $49.8 \%(\mathrm{~N}=427)$ and female respondents constituting $50.2 \%(\mathrm{~N}=431)$, almost equal in proportion $(50 \%)$.

\subsection{Research Questions}

Q. 1: What is the level of usage of mobile phone among university students from a gender perspective?

Q. 2: What are the patterns of mobile phone use among university students from a gender perspective?

Q. 3: What are the purposes of using mobile phone with respect to gender?

\section{Results and Analysis}

Each question is dealt with in a detailed answer along with the presentation of results and discussion as:

\section{Q 1: What is the level of usage of mobile phones among university students from a gender perspective?}

This research question aimed at exploring the use of mobile phones among male and female university students. In this study, the usage was operationally defined as the usage and the period of usage of mobile phones, whereas usage included both use and non-use of mobile phone.

\subsection{Usage of Mobile Phones from a Gender Perspective}

In order to find out the usage of mobile phones among male and female university students, they were asked whether they had been using mobile phones or not. The summary of the responses of both male and female students is presented in Figure 1.

It is evident from the Figure 1 that the usage of mobile phone was very high among Pakistani university students at $90.8 \%$. Among the users, the numbers of male and female students were $92.9 \%$ and $88.7 \%$ respectively. Similarly, among non-users, the numbers of male and female students were $7.1 \%$ and $11.3 \%$ respectively. The ratio of female users of mobile phone was low as compared to male users. Social hindrances, especially of parents, could be a valid reason for the low ratio of female users of mobile phones, rather than inexperience and disinterest.

However, it is evident from the findings of the study that the usage of mobile phones among university students was increasing. One reason for high use could be the affordability of the mobile phone due to its low price when compared to computers. 


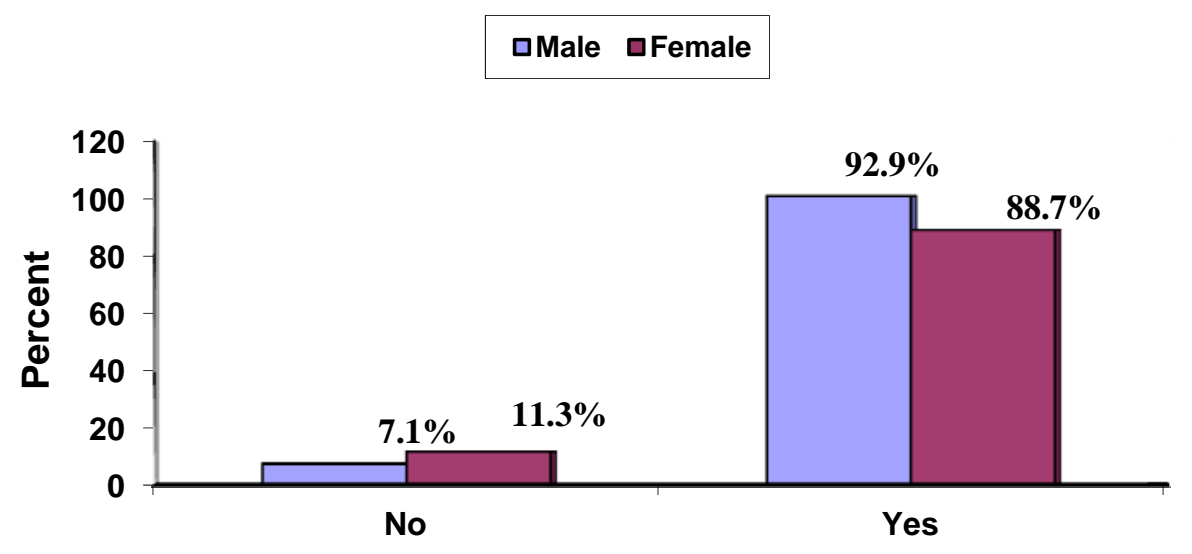

Figure 1. Bar graph of users and non-users of mobile phone with respect to gender

\subsection{Years of Mobile Phone Use}

To explore the usage of mobile phone among university students, they were asked how long they had been using mobile phones. The difference in periods of usage between male and female students is presented in the bar chart in Figure 2.

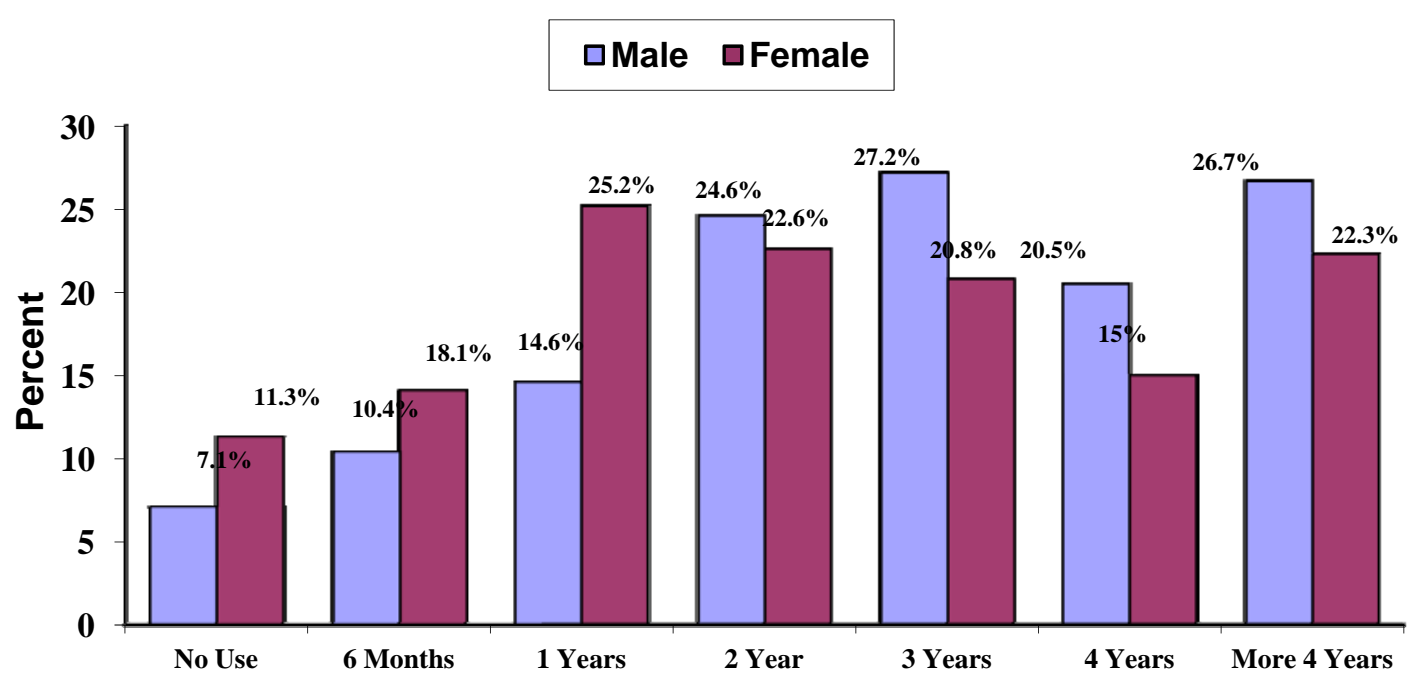

Figure 2. Bar graph of total period of mobile phone use with respect to gender

The ratio of male students who started using mobile phones more than four years ago was $26.7 \%$ while that of the females, for the same period, was $22.3 \%$. Among mobile phone users who had been using mobile phones for two to three years, and even four years and more than four years, the number of male students was greater. It means that in the early usage of mobile phones, male students exceeded female students. The reason, as mentioned earlier, might be that males in Pakistani society generally have more access to different resources like computer, the Internet, computer labs and mobile phone and can have more interaction with others as compared to females.

The data reveals that the period of usage of mobile phones has an impact on the users and it is also apparent from it that with the passage of time among new adopters and users females were superseding males. Among the mobile phone users whose usage period was up to one year, the ratio of female users was $25.2 \%$ whereas that of male users was $14.6 \%$. It indicates that in the very recent period, the number of females is greater than that of the males.

JTI Vol. 1, No. 2, July $2013: 59-68$ 
There was the tendency to use mobile phones had been increasing among females more than males. There were many cultural and social factors for this varying level of usage of mobile phone among females.

\subsection{Expenditure on the Use of Mobile Phone per Month}

Students were asked how much they spent on mobile phone per month. The question explored the expenditure on the use of mobile phone among male and female university students. The following Figure 3 presents the summary of the responses.

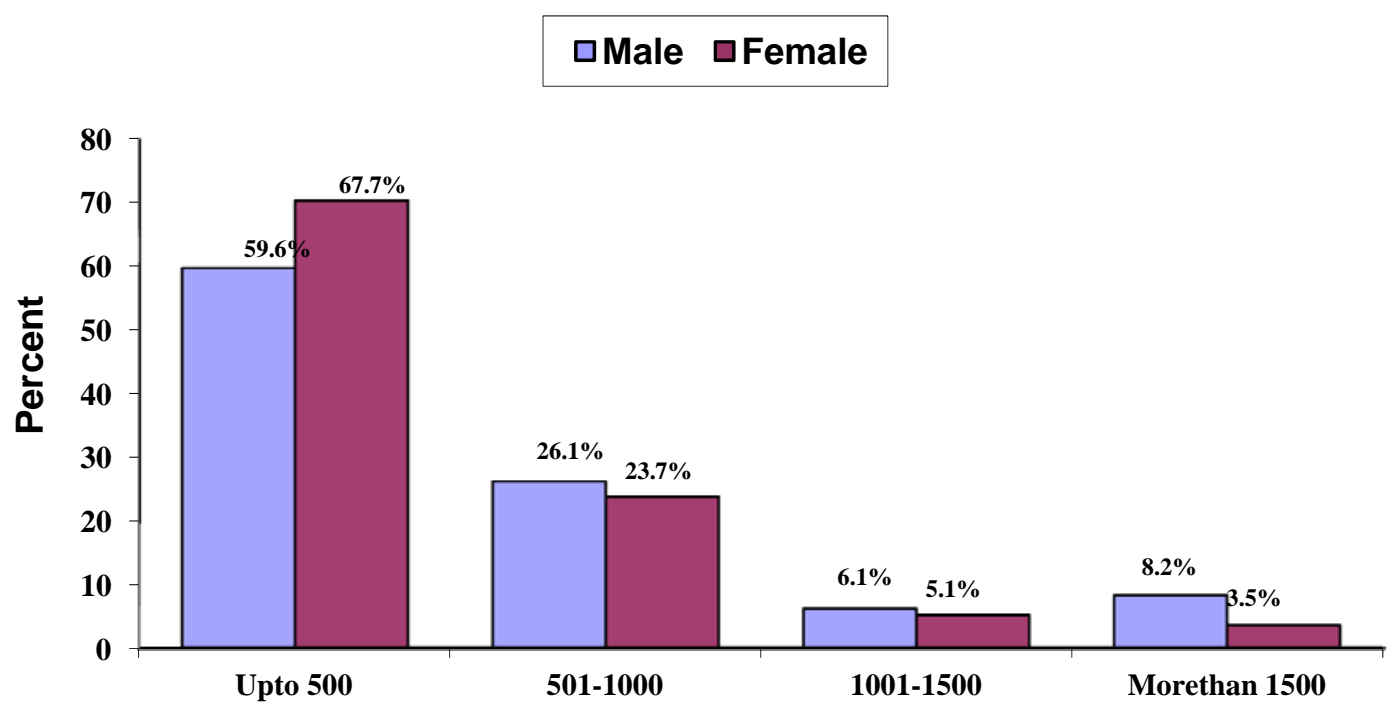

Figure 3. Bar graph of money spent on the use of mobile phone per month with respect to gender

The majority of male and female students spent up to Rupees 500 in a month on the use of mobile phone. The figure reveals that $67.7 \%$ of females and $59.6 \%$ of males were spending up to Rupees 500 per month on the use of mobile phone, and this was the only section in which females led. While those who spent Rupees five hundred and one, or more, were led by the males.

The reason for males spending more money on mobile phone use could be that they were in the habit of making more and longer duration calls (See Figure 1.4) for they were supposed to be having more friends. The male students also had to contact their family members as they, in most of the cases, had to live in hostels, away from their homes. Males also developed some relations with females while studying at university. In most cases, these were males who opted to contact their female friends in Pakistan. All these causes gave rise to their monthly expenses incurred on the mobile phone use.

\section{$Q$ 2: What are the patterns of mobile phone' use among university students from a gender perspective?}

This research question aimed at finding out the gender difference regarding the patterns of mobile phone use. In this study, the following aspects had been probed within the patterns of mobile phone use:

- the time spent each day on the use of mobile phone;

- the extent of text messaging and making calls;

- the preferred time of mobile phone usage.

In order to ascertain whether there were any differences between the two genders for patterns of mobile phone use; findings were presented in the form of bar graphs. 


\subsection{Duration of Mobile Phone Call}

To explore the time spent by both male and female students on mobile phones, they were asked how long their calls were from mobile phone. Their responses appear in Figure 4.

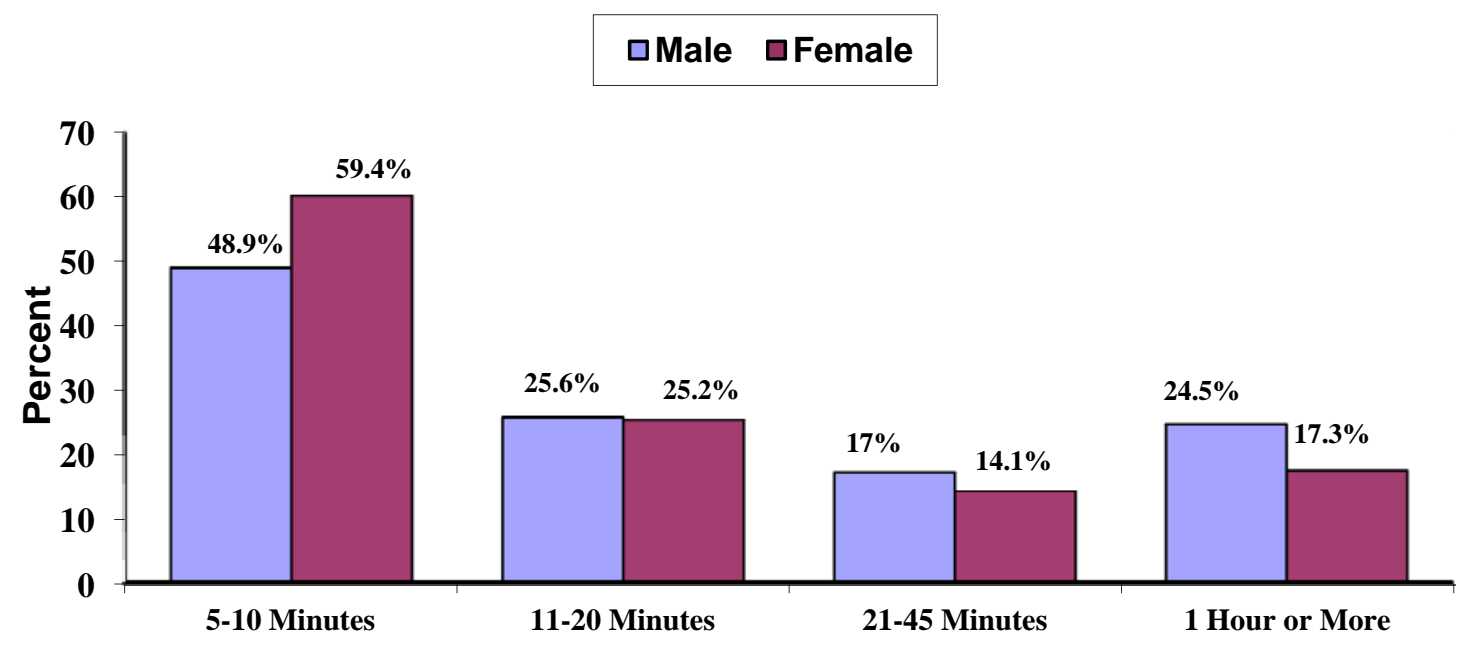

Figure 4. Bar graph of Duration of time spent on Mobile phone per call with respect to gender

Figure 4 shows that most male and female students conversed on their mobile phones for 5 to 10 minutes and $59.4 \%$ of female students and $48.9 \%$ of male students spent 5 to 10 minutes while talking to others on their mobile phones. Nevertheless, there was not much gender difference in call duration of 11 to 20 minutes. Of those who made calls for more than 20 minutes, the ratio of male participants was higher compared to female participants.

There is a conventional opinion about females that they talk too much and can keep talking for hours and hours. But contrarily it is evident from Figure 1.4 that there were fewer females who made calls of long duration. A reason might have been that female students were more conscious of their mobile phone expenditures or they have less money to spend on their mobile phone bills. Another reason could be that Pakistani parents most of the time did not like their grown up daughters to be unnecessarily busy with their mobile phones. Though the universities are hubs of students from moderate Pakistani society, the female university students nevertheless did not feel comfortable talking for longer periods of time on mobile phone as compared to males.

\subsection{Average Number of Calls on Mobile Phone per Day}

Students were asked how many times they made calls from mobile phone in a day. The question explored the extent of the use of mobile phone among male and female university students. Figure 5 presents the summary of the responses.

Among university students who made calls from 1 to 4 times a day, the ratio of females was higher with $65.4 \%$ than that of males (40.4\%). Male students were greater in number among those making calls from 5 times to more than 12 times a day. This result of the present study is in line with the cross-national study of mobile phone use by university students in Sweden, the United states, Italy, Japan and Korea where male students were engaged more in making more calls per day than female students [16].

It was evident in the findings that even those who were making calls 9 to 12 times or even more than 12 times per day were quite significant in number. But interestingly, the figure reveals that the tendency of making more calls per day was greater among male university students. It can be inferred from the study that those who have mobile phone addiction make more calls [17].

JTI Vol. 1, No. 2, July 2013 : $59-68$ 


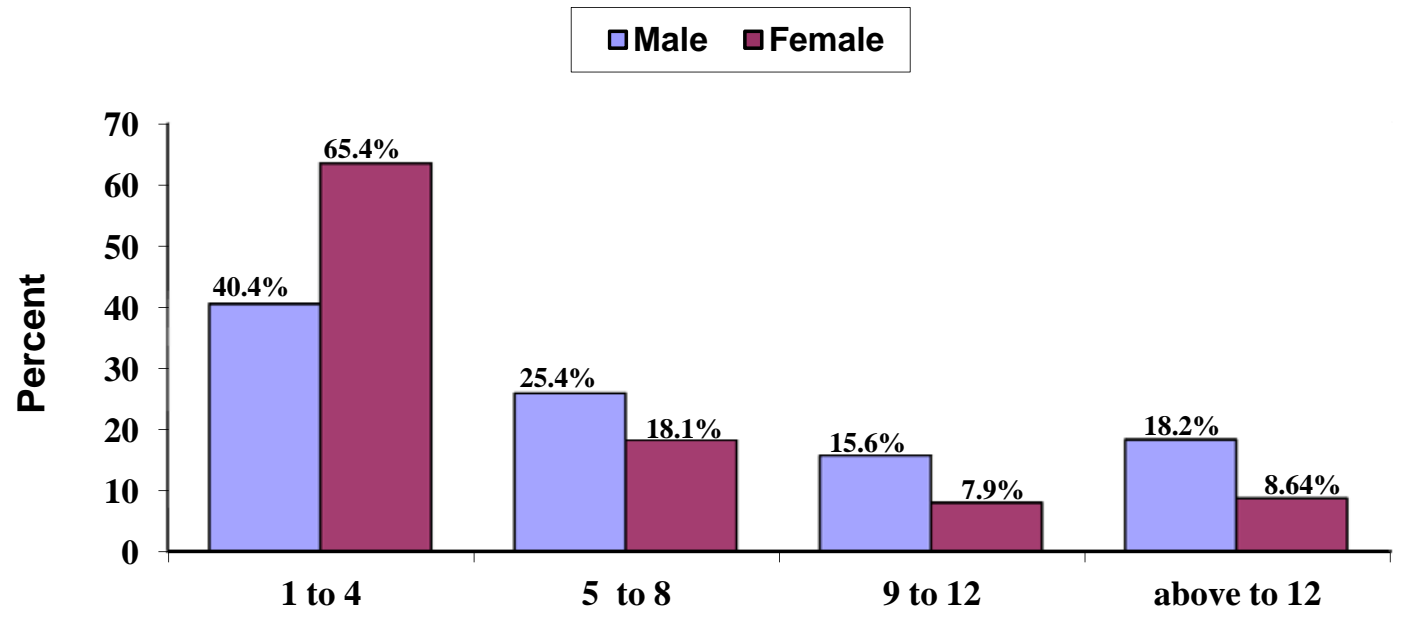

Figure 5. Bar graph of average number of calls on mobile phone per day with respect to gender

\section{Average Number of Text Messages Sent per Day}

To measure the extent of use of SMSs or text messages, the respondents were asked how many text messages they sent in a day. Their responses appear in Figure 6.

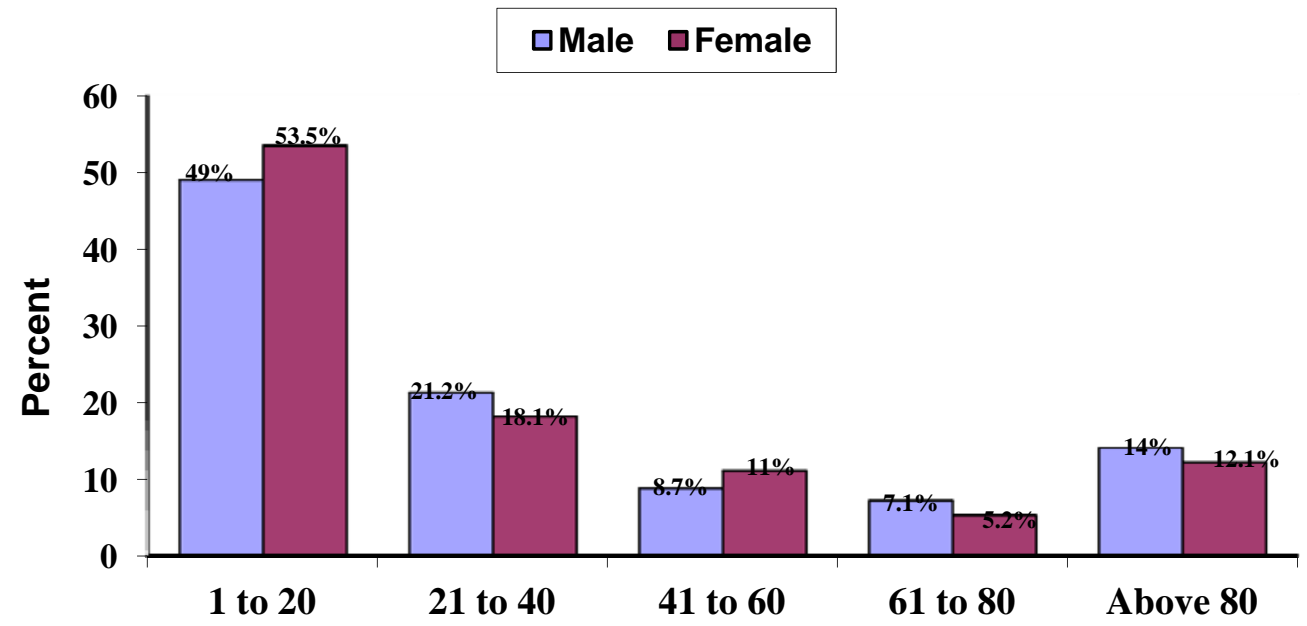

Figure 6. Bar graph of average number of text messages sent per day with respect to gender

The ratio of female students who sent 1 to 20 text messages was $53.5 \%$ and that of males in the same category was $49 \%$. The male students who sent more than 60 text messages were greater in number than females.

The findings revealed that there was not a sharp gender difference regarding the use of text messages among male and female university students. However, Taiwanese female students showed addiction to the use of mobile phones and they sent more text messages [17]. A considerable percentage of respondents sent text messages in larger numbers i.e. more than 80 per day. A reason might have been that students subscribed to cheap packages of SMSs offered by various cellular network operators [18]. The results could also be inferred that the students wanted to be in touch with others all the time and for that purpose, they used text messages. The present study results are in line with another study conducted on urbanized Malaysian youth to gauge mobile phone and SMS appropriation, usage and behavioural issues among university students showing that SMS were used to organize social appointments and to keep in touch with families and friends [19]. In Pakistan, SMS is considered a new phenomenon of interpersonal communication and is gaining more popularity among youth as it is taken as the cheapest way of contacting one another anytime and anywhere. 


\subsection{Preferred Timing of Mobile Phone Use}

Students were questioned to find out their preferred timings for using mobile phones. The summary of their responses is presented in Figure 7.

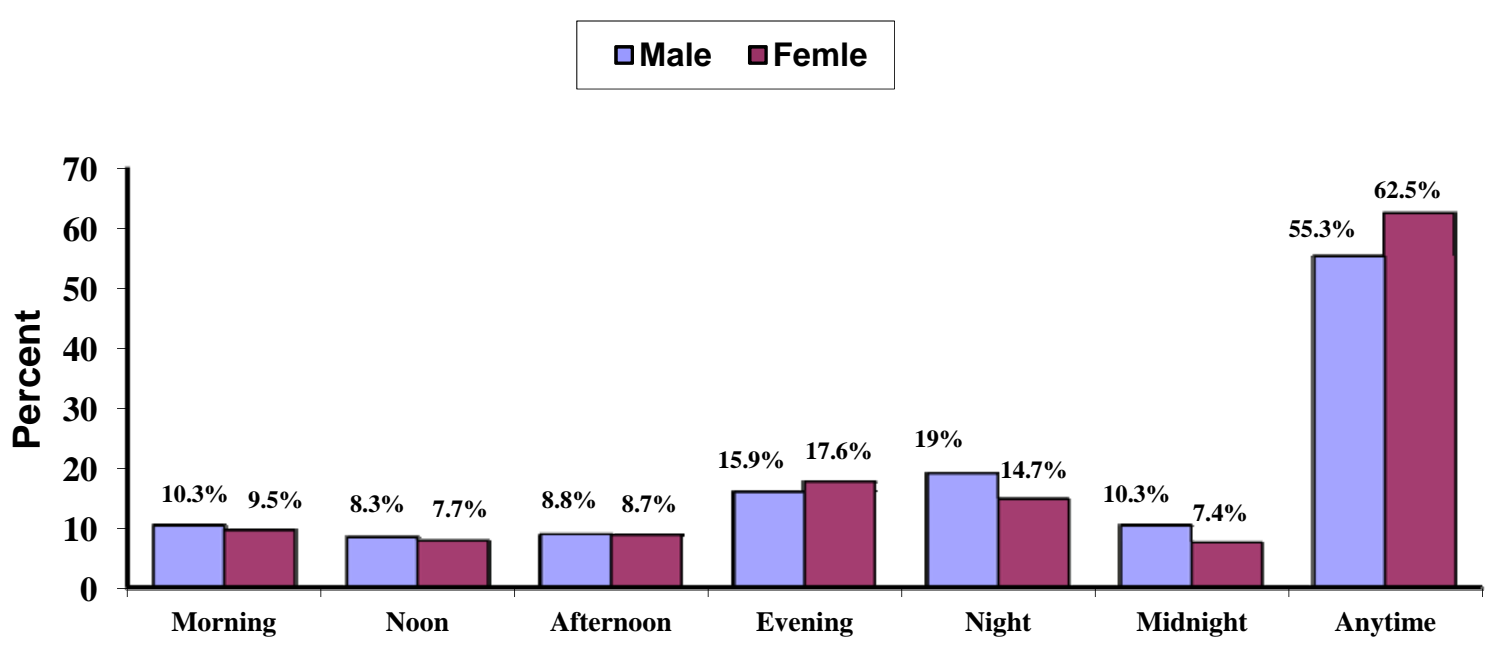

Figure 7. Bar graph of preferred time for the use of mobile phone with respect to gender

Figure 7 reveals that the majority of both male and female students used mobile phone anytime. The male students who used mobile phones any time (not any specific time) were $55.3 \%$ and female users were $62.5 \%$. Among the rest of the time, evening and night were the more preferred timings for mobile phone usage. The mobile phone was less used by the female students than by male students at night and midnight. It might have been because of the taboos in some families that did not allow females to use mobile phones at night.

\section{Q 3: What is the purpose of sharing text messages with respect to gender?}

\subsection{Purpose of using mobile phone}

Students were questioned regarding their purposes for using mobile phones. The findings in Figure 8 summarise the issues discussed by both male and female university students while talking on mobile phones with others.

The findings show that the most frequent issues discussed with others by both genders were personal, and related to friendship, entertainment and academics. $22.2 \%$ of females and $17.8 \%$ of males also discussed religion with others while $22.2 \%$ of males and $14.4 \%$ of females discussed political issues, which showed that besides religion and politics, their major concerns during talk remained personal, friendship and entertainment. This was why civil society and especially religious people, did not like youth s' use of mobile phones. Generally, people believed that youngsters used mobile phone for chatting and for friendship, especially with the opposite sex, much more than revealed in this research.

Since Pakistanis belong to a conservative society and there are many strict social and religious taboos hindering their ways of open friendship between males and females, in the presence of mobile phone facility- it is natural for the youth to use mobile phones to reduce their loneliness and create friendship. The use of mobile phone encouraged both males and females to make friendships, especially with the opposite sex, which provided a platform for expressing and introducing themselves to others. Through chatting, they developed some type of acquaintance and dared to discuss their very personal matters as well. So chatting on mobile phone became an excellent platform for their catharsis. The users were more open to discuss their personal issues and problems with their friends than during face to face communication. In a way, mobile phone reduced suppression of youth's emotions and provided them with an outlet for expressing their ambition, desire, likes and dislikes. It helped decrease negative attitudes among youth and provided solutions to many social, psychological and biological problems.

JTI Vol. 1, No. 2, July 2013: $59-68$ 


\section{$\square$ Male $\square$ Female}

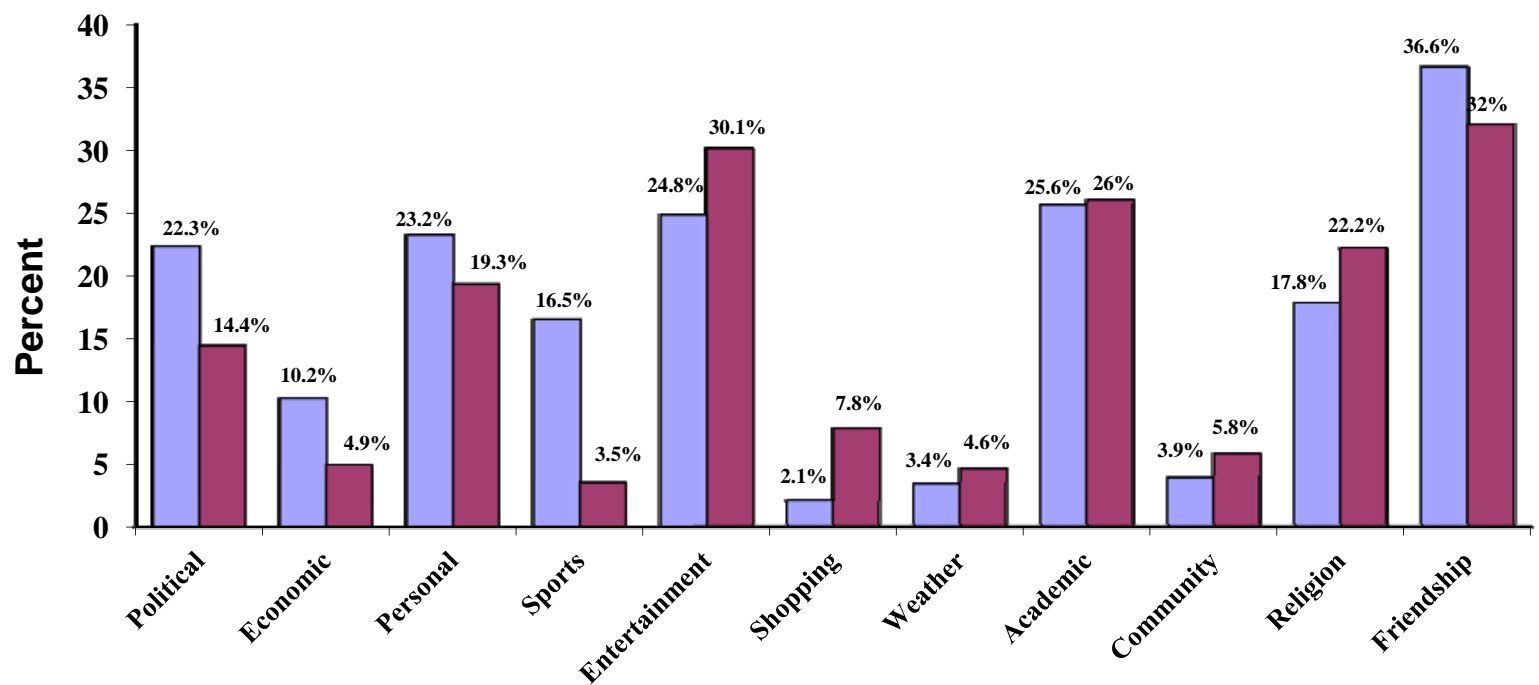

Figure 8. Bar graph of purposes for using mobile phone with respect to gender

Both male and female students talked about political issues. It could be the reason that students had easier access to mobile phone and were more likely to discuss political issues as well.

\subsection{Purpose of Sharing Text Messages}

To explore the purpose of sharing text messages, students were asked to describe the type of text messages which they sent. The findings are placed in Figure 9.

\section{口Male 口Female}

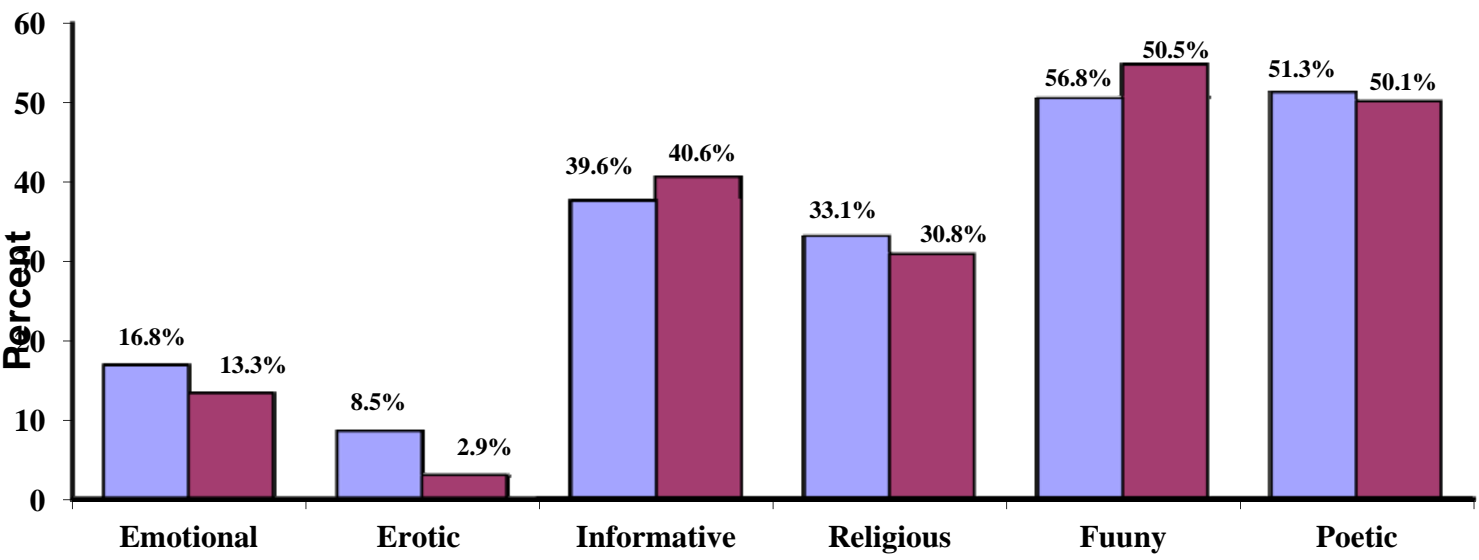

Figure 9. Bar graph of information shared through text messages with respect to gender

The findings revealed that the main areas shared through text messages by the youngsters were poetic and funny, and that these were followed by information and religious matters. The least frequent types of information sent through text messages were emotional and 
erotic. Females expressed more interests in sending informative and funny text messages as compared to males, while the number of males was larger in the rest of the categories.

\section{Conclusion}

It can be concluded from the findings that gender differences do exist in usage, purpose and patterns of using mobile phone, though most of the time, they are not so wide. There is a change in trend in the usage of mobile phones, according to which females are now increasingly tending to adopt the mobile phone. The patterns of mobile phone usage among the university students show that females are almost equally on a par with males, which is unexpected situation in Pakistani society. So far as the purposes of mobile phone usage are concerned, the gender stereotypes prevailing in Pakistani society have remained the same in some places while in other, they have been challenged, as mobile phone have brought change to the lives of young people.

\section{References}

[1] Walsh, S. and K. White, Ring, ring, why did I make that call? Mobile phone beliefs and behaviour among Australian university students Youth Studies Australia, 2006. 25(3): p. 49-57.

[2] Lasen, A., Understanding mobile phone users and usage. 2005, Vodafone Group R and D ( Electronic Version).

[3] Holloway, S.L. and G. Valentine 'It's only as stupid as you are': Children's and adults' negotiation of ICT competence at home and at school. Social \& Cultural Geography 2001. 2(1): p. 25-42.

[4] Yoon, K., The making of neo-Confucian cyberkids:representations of young mobile phone users in South Korea. New Media \& Society, 2006. 8(5): p. 753-771.

[5] 5. Nomura, K., Socio-spatial implications of American university students' cell-phone consumption: multiple connections, personal management, and social negotiations. 2006, The Pennsylvania State University.

[6] Ogunyemi, O. Consumption and (in) appropriate use of mobile phone among teenage Africans in the UK. In 2nd International Conference on Pluridisciplinary Perspectives on Child and Teen Consumption. 2010.

[7] Lipscomb, T.J., et al., Cellular phone etiquette among college students. International Journal of Consumer Studies (DOI:10.1111/j.1470-6431.2005.00483.x), 2005. 31(1): p. 46-56.

[8] Isa, K.A.M., et al., Mobile Phone Usage Behaviour while Driving among Educated Young Adults in the Urban University. Procedia - Social and Behavioral Sciences, 2012. 36: p. 414-420.

[9] Hislop, D., Hanging on the telephone: Mobile phone use patterns among UK-based business travellers on work-related journeys. Transportation Research Part F: Traffic Psychology and Behaviour, 2012. 15(2): p. 101-110.

[10] Ojo, O.D., N.O.A. Ugochukwu, and E.J. Obinna, Youthful Lust and Violation of Mobile Phone Rule In a Private Christian Mission University, South West Nigeria. World Journal of Education, 2011. 1(2): p. 49-61.

[11] Turner, M., S. Love, and M. Howell, Understanding emotions experienced when using a mobile phone in public: The social usability of mobile (cellular) telephones. Telematics and Informatics, 2008. 25(3): p. 201-215.

[12] Ling, L.H., Constructing learning conversations: A Study of the discourse and learner experiences of online synchronous discussions. 2006, Murdoch University.

[13] Jamal, A., et al., Patterns of use of 'smart phones' among female medical students and self-reported effects. Journal of Taibah University Medical Sciences, 2012. 7(1): p. 45-49.

[14] Haverila, M., Cell phone usage and broad feature preferences: A study among Finnish undergraduate students. Telematics and Informatics, 2013. 30(2): p. 177-188.

[15] Pettigrew, J.L., Mobile text messaging and connectedness within close Interpersonal Relationships, in Department of Communication Studies. MA Thesis.Indiana University; 2007.

[16] Baron, N.S. and E.M. Campbell, Gender and mobile phones in cross-national context. Language Sciences, 2012. 34(1): p. 13-27.

[17] Hong, F.-Y., S.-I. Chiu, and D.-H. Huang, A model of the relationship between psychological characteristics, mobile phone addiction and use of mobile phones by Taiwanese university female students. Computers in Human Behavior, 2012. 28(6): p. 2152-2159.

[18] Walsh, S.P., et al., Keeping in constant touch: The predictors of young Australians' mobile phone involvement. Computers in Human Behavior, 2011. 27(1): p. 333-342.

[19] Balakrishnan, V. and H.-S. Loo, Mobile Phone and Short Message Service Appropriation, Usage and Behavioral Issues among University Students. Journal of Social Sciences, 2012. 8(3): p. 364-371.

JTI Vol. 1, No. 2, July 2013: $59-68$ 